\title{
Study of the Insecticidal Potential of Diatomaceous Earth from Sig (Algeria) on the Dermestes haemorrhoidalis - A Pest of Stored Food Products
}

\author{
A. Djadi*,**†, M. Bouzid* and B. Bezzazi* \\ * Unité de Recherche Matériaux, Procédés et Environnement/Université M'Hamed Bougarra, Boumerdes, Algérie, \\ Avenue de l'indépendance, 35000, Boumerdès, Algérie \\ ** Unité de Recherche en Analyse et Développement Technologique en Environnement, Centre de Recherche \\ Scientifique et Technique en Analyses Physico-Chimiques, Bousmail, BP 384, Zone Industrielle Bou-Ismail RP 42004, \\ Tipaza, Algérie \\ †Corresponding author: A. Djadi; a.djadi@univ-boumerdes.dz
}

Nat. Env. \& Poll. Tech.

Website: www.neptjournal.com

Received: 20-04-2020

Revised: 20-05-2020

Accepted: 25-06-2020

Key Words:

Dermestes haemorrhoidalis

Diatomaceous earth

Insecticidal activity

Natural insecticide

\begin{abstract}
The insecticidal activity of the Diatomaceous Earth (DE) of Sig was assessed against the Dermestes haemorrhoidalis, which is the main pest affecting wheat stored in Blida, a central region of Algeria and one of the four cereal regions managed by the Algerian Inter-branch Cereals Office (AICO). The formulation was tested at two different doses: 500 and 1000 ppm against adults of the species. The bioassays were carried out in 1-litre glass jars containing soft wheat with an average moisture content of $60 \%$ mixed with diatomaceous earth and maintained at $27^{\circ} \mathrm{C}$ and $70 \%$ of humidity. The effectiveness of the treatment was assessed by recording adult mortality after 2, 7 and 14 days. Sig's diatomite showed significant insecticidal activity against Dermestes haemorrhoidalis after only two days of treatment with both doses 500 and 1000 ppm. After 14 days, average mortality was more than $95 \%$ even at $500 \mathrm{ppm}$. Furthermore, electron microscopy of the diatomite particle from Sig (Algeria) reveals the architecture of the frustule. It shows a porous and brittle siliceous shell made largely of diatomite "skeletons". This research work allowed getting insights into the mechanism of action of diatomite on the Dermestes haemorrhoidalis. On the other hand, the identification of diatomite of Sig was performed

by X-ray diffraction and infrared.
\end{abstract}

\section{INTRODUCTION}

Chemical pesticides are widely used around the world. Their negative impact on animal and plant health has been widely highlighted in the literature (Testud \& Grillet 2007, Hazarika 2011, Ghorab \& Khalil 2016, Richardson et al. 2019). Metabolites from carbamates and phosphines, which are toxic substances, persist in nature in large quantities (Meiniel 1977, Steeve 2013, Lotti \& Moritto 2005, Martin-Reina et al. 2017). The control of insects that destroy stored food still relies on chemicals, but following the growing concerns regarding the issue, a renewed interest in Diatomaceous Earth (DE) has been shown in recent years in the field of applied sciences (Ebadollahi \& Sadeghi 2018, Athanassiou et al. 2016). This is particularly the case for the disinfection of premises and protection of stored food (Banks \& Fields 1995, Bridgeman 1998, Desmarchelier et al. 1992, Korunić et al. 2016). Indeed, DE has long been used to protect the stored grain. These fossils give, after extraction, crushing and grinding, a fine powder primarily composed of amorphous silicon dioxide $\left(\mathrm{SiO}_{2}\right)$ with a small amount of aluminium, iron, magnesium, $\mathrm{CaO}$ and sodium oxide. The highly porous, inert and sharp architecture of the frustules of the DE is used for its abrasive and desiccating properties (Quarles \& Winn 1996, Korunić et al. 2016).

The insecticidal activity of DE is essentially attributed to dehydration of the insect provoked by damage to the cuticle layers of the integument. The DE particles are trapped on the insect's body and absorb lipids in the waxy layer of the epicuticle causing degradation of the exoskeleton (Ebeling 1971, Korunić et al. 2016, Mewis \& Ulrichs 2001).

However, insecticidal efficiency depends significantly upon the physical, chemical and morphological characteristics of the diatomite species in DE (Korunić et al. 2016, Rojht et al. 2010) and particle size (Korunić 2013, Subramanyam $\&$ Roesli 2000). It also depends upon the resistance of the host insects (Aoues et al. 2017).

The use of DE to control food pests offers a number of advantages: it does not leave chemical residues, has low toxicity, is inexpensive and can be easily disposed (Korunić et al. 2016). DE has been used to treat wheat contaminated with C. ferrugineus. It has also been used for the elimination of Sitophilus oryzae and red flour beetle Tribolium castaneum 
Herbst from rice and wheat (Korunic et al. 2016).

The objective of this paper is to describe the physicochemical analysis of Sig's DE and to carry out a preliminary test regarding pest control potential on food pests under natural storage conditions in the hot and humid region of Blida, Algeria.

\section{MATERIALS AND METHODS}

\section{Preparation of the Samples}

The diatomite used in this work is a raw Algerian white diatomite from the National Company of Mining Products Non-Ferrous and Useful Substances (ENOF) deposit located at $5 \mathrm{Kms}$ from southeast of the city of Sig in the Wilaya (province) of Mascara, hereafter referred to as diatomite of Sig (DTS). The collected diatomite samples were crushed and dried, ground as finely as possible and sieved to a particle size less than $63 \mu \mathrm{m}$. The obtained products were subject to physicochemical, spectroscopic and structural characterization, and used in all the experiments.

White grains used in the experiments were first sieved to remove impurities and then stored hermetically in glass jars at room temperature.

An experimental unit consisted of a glass jar containing $1 \mathrm{~kg}$ of soft wheat, to which DTS powder was added and then carefully hand-mixed. Fifty (50) adult insects
(Dermestes haemorrhoidalis), Dermestidae family and Beetles order, 2 weeks old on average, was introduced into the jar. The same procedure was followed for each concentration of DTS with an interval of 2, 7 and 14 days of exposure.

An additional jar containing untreated wheat was used (as control sample) for each series of tests. Three treated samples: $500 \mathrm{ppm}, 1000 \mathrm{ppm}$ and control (untreated) were used for each time interval. After 2, 7 and 14 days of exposure, the contents of the jars were screened, living and dead insects were collected and counted. Mortality is expressed as a percentage of adult deaths out of the total number of beetles found in each jar. The experiments were carried out from May to July 2019.

The Dermestes haemorrhoidalis adults used for the experiments were obtained from a wheat stock in the region of Blida. The insects were kept under the same infestation conditions at a temperature of $25 \pm 1{ }^{\circ} \mathrm{C}$ and relative humidity (RH) of \%60 on average. Identification of the pest was carried out using a key developed by Oleobel and Tran, (1993). The species are stored food beetles: black beetle of the pantry (Dermestes haemorrhoidalis) (Fig. 1).

\section{Characterization of DTS}

The X-ray diffraction (XRD) analysis of the DTS powder was carried out using a BRUKER D8 ADVANCE Eco,
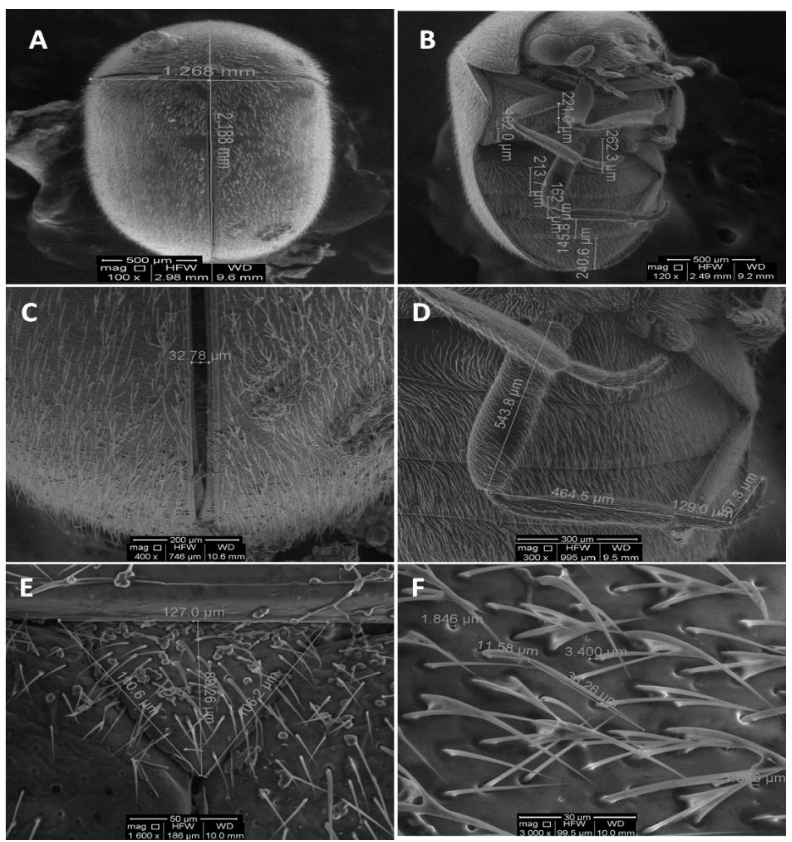

Fig. 1: SEM observation of untreated Dermestes haemorrhoidalis, A, C and E: dorsal side, B and D: ventral side, F: Dorsolateral face showing cuticular thoracic depressions surrounding the sensory bristles. 
equipped with a $\mathrm{Cu}$ anticathode $(\lambda=1.5418 \AA)$ generating a power of $40 \mathrm{~mA}, 45 \mathrm{KV}$ and mode 2 THETA, scanning area [3.0001- $89.999482^{\circ}$ ], a step of $0.020171^{\circ}$, time per step: $0.5 \mathrm{~s}$. Software for the acquisition and processing of data are respectively: Data Collector and High Score Plus of PANalytical.

To study the thermal properties of DTS, samples of (2 mg) were measured using the SeikoSSC5200 thermal analyser (model 220 TG/DTA) at heating and flow rates of $10-50^{\circ} \mathrm{C} / \mathrm{min}$ and $100 \mathrm{~mL} / \mathrm{min}$, respectively. Analysis and data processing software are TA Instrument Explorer and TA Universal Analysis, respectively.

DTS grain scanning electron microscopy was performed with a Quanta 250 from FEI and a tungsten filament as an electron source.

The infrared absorption spectra were plotted with a BRUKER Alpha type device; the analysis was done in ATR mode with a resolution of $2 \mathrm{~cm}^{-1}$ for 24 scans.

The elementary analysis of DTS was carried out with Rigaku ZSX Primus II X-ray Fluorescence Spectrometer, elementary coverage: ${ }^{4} \mathrm{Be}$ à ${ }^{92} \mathrm{U}$. Closing window, Rh-anode, $3 \mathrm{~kW}$ or $4 \mathrm{~kW}, 60 \mathrm{kV}$. Primary X-ray filter: Al25, Al125, Ni40 and Ni400. Heavy Element Detector: Scintillation Counter (SC).

The volumetric distribution of DTS was assessed by laser granulometry using MALVERN MATERSIZER 2000 granulometer equipped with Scirocco as a dry dispersion accessory; sensitivity normal, absorption 0.1 and obscuration $5,68 \%$.

\section{Statistical Analysis}

ANOVA was used to evaluate the treatment and exposure time of DTS on mortality of Dermestes haemorrhoidalis. The results are presented as mortality percentage of Dermestes haemorrhoidalis at $500 \mathrm{ppm}$ and $1000 \mathrm{ppm}$ of DTS, respectively and the exposure time of 2, 7 and 14 days respectively.

\section{RESULTS AND DISCUSSION}

Phase quantification of DTS by XRD analysis was conducted using MAUD software as illustrated in Fig. 2. DTS powder consists of amorphous and crystalline phases. The main constituents of crystalline phases are $\mathrm{CaCO}_{3}, \mathrm{SiO}_{2}$, $\mathrm{Al}_{2} \mathrm{O}_{3}, \mathrm{Fe}_{2} \mathrm{O}_{3}$ on the MAUD database records. The results agree with the result obtained by Pokorný et al. (2017).

The SEM of DTS (Fig. 3) shows the pores and the cylindrical and/or disc form of this powder. The average size of the diatomite particles determined by laser granulometry

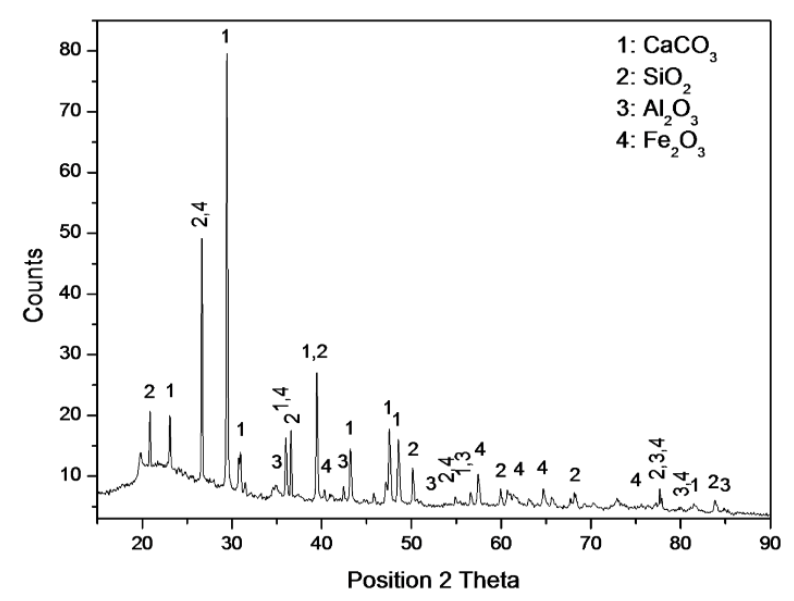

Fig. 2: X-ray diffraction pattern of diatomite of Sig (DTS).

is $\sim 12 \mu \mathrm{m}$ (Fig. 4), with a specific surface area of 1.61 $\mathrm{m}^{2} / \mathrm{g}$. the average particle diameter is in the range 3,802 $34,674 \mu \mathrm{m}$; similar results were obtained by Fragoulis et al. (2005) where they found a diameter $<30 \mu \mathrm{m}$.

The elemental composition of DTS was obtained by $\mathrm{X}$-ray Fluorescence (XRF); the fire loss is $7.4 \%$ and the moisture content is $2.5 \%$. Results of the chemical analysis of the material (Table 1) show that the diatomite is largely made up of silica, $\mathrm{CaO}$ and aluminium oxide. Other elements are present but in much smaller amounts.

Fourier Transform Infrared Spectroscopy (FTIR) analysis of DTS (Fig. 5) shows the main absorption bands of our untreated diatomite are in agreement with the literature (Yuan et al. 2004, Caliskan et al. 2011). Indeed, the wide band in the wave number range $3100-3500 \mathrm{~cm}^{-1}$ characterizes the vibration of the $\mathrm{OH}$ group of water contained in the DTS, as well as the $\mathrm{Si}-\mathrm{OH}$ group, which are observed at 3690 and $3614 \mathrm{~cm}^{-1}, \mathrm{OH}$ and $\mathrm{Si}-\mathrm{OH}$, respectively. The weak vibration at $3600 \mathrm{~cm}^{-1}$ indicates the presence of unbound water, i.e. free $\mathrm{OH}$. On the other hand, water deformation appears at $1640 \mathrm{~cm}^{-1}$ (Yuan et al. 2004) while vibrations centred at 1440,875 and $712 \mathrm{~cm}^{-1}$ indicate $\mathrm{CO}_{2}$ deformation (Yuan et al. 2004, Caliskan et al. 2011). The characteristic peaks of the skeleton $\left(\mathrm{Si}-\mathrm{O}-\mathrm{Si}\right.$ ) are located at 1073 and $997 \mathrm{~cm}^{-1}$ (Caliskan et al. 2011). The band centred at $874 \mathrm{~cm}^{-1}$ corresponds to the elongation vibration of the silanol group ( $\mathrm{Si}-\mathrm{O})$. The peaks at 798 and $713 \mathrm{~cm}^{-1}$ are due to $\mathrm{Si}-\mathrm{O}-\mathrm{H}$ vibrations. The absorption peak around $570 \mathrm{~cm}^{-1}$ can be assigned to the deformation vibration of the entity $\mathrm{Si}-\mathrm{O}-\mathrm{Si}$. The intense band at $460 \mathrm{~cm}^{-1}$ is relative to the angular vibration of $(\mathrm{Si}-\mathrm{O}-\mathrm{Al})$ and /or ( $\mathrm{Si}$ - O - Si) (Caliskan et al. 2011).

Results of the simultaneous thermogravimetric analysis (TGA) and differential scanning calorimetry (DSC) analysis of the DTS are shown in Fig. 6. The evolution of diatomite in 


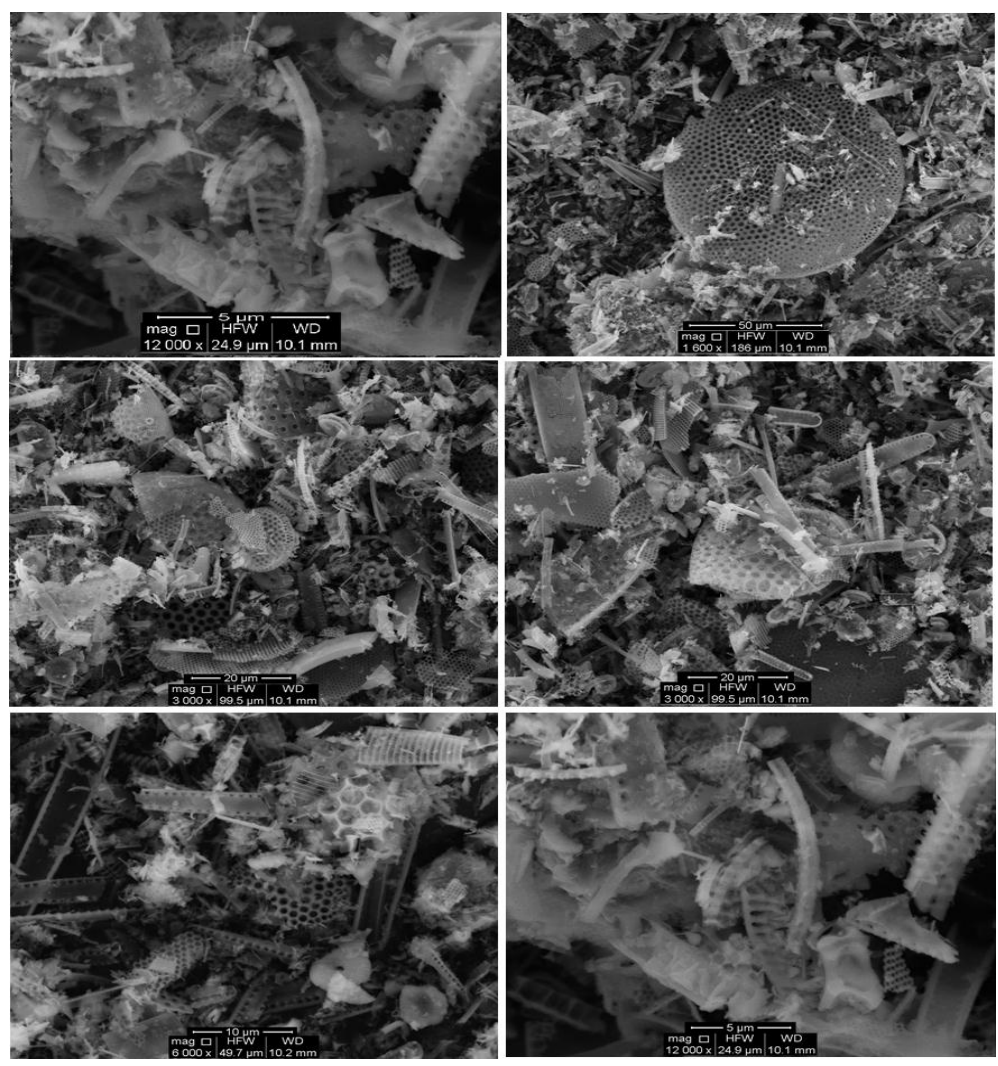

Fig. 3: SEM observation of the diatomite of Sig (DTS) at different magnifications.

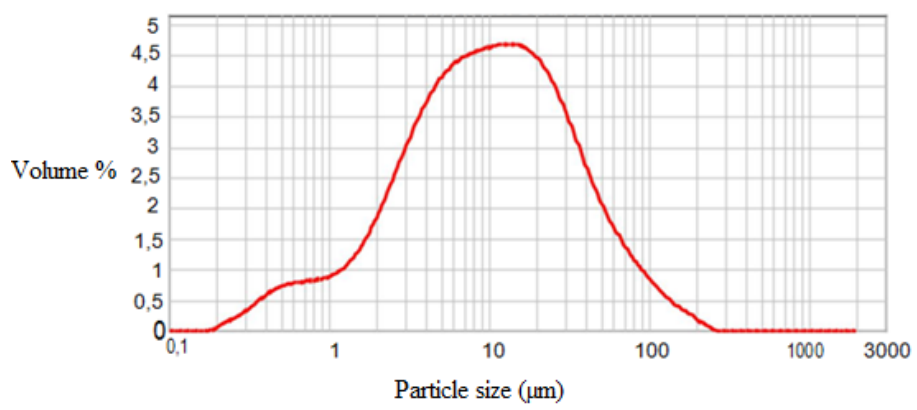

Fig. 4: Particle size distribution of diatomite of Sig (DTS).

Table 1: Chemical composition of diatomite of Sig.

\begin{tabular}{|c|c|c|c|c|c|c|c|c|c|}
\hline \multicolumn{10}{|c|}{ Constituent and weight $\%$} \\
\hline $\mathrm{CO}_{2}$ & $\mathrm{Na}_{2} \mathrm{O}$ & $\mathrm{MgO}$ & $\mathrm{Al}_{2} \mathrm{O}_{3}$ & $\mathrm{SiO}_{2}$ & $\mathrm{P}_{2} \mathrm{O}_{5}$ & $\mathrm{SO}_{3}$ & $\mathrm{~K}_{2} \mathrm{O}$ & $\mathrm{CaO}$ & $\mathrm{TiO}_{2}$ \\
\hline 9.40 & 0.26 & 1.27 & 3.87 & 64.08 & 0.16 & 0.08 & 0.89 & 17.64 & 0.26 \\
\hline \multicolumn{10}{|c|}{ Constituent and weight $\%$} \\
\hline $\mathrm{MnO}$ & $\mathrm{Fe}_{2} \mathrm{O}_{3}$ & $\mathrm{NiO}$ & $\mathrm{ZnO}$ & $\mathrm{Rb}_{2} \mathrm{O}$ & $\mathrm{SrO}$ & $\mathrm{ZrO}_{2}$ & $\mathrm{Cl}$ & & \\
\hline 0.01 & 1.77 & 0.01 & 0.01 & 0.01 & 0.05 & 0.01 & 0.15 & & \\
\hline
\end{tabular}

the TGA agrees well with the literature (Meradi et al. 2015, Mendioroz et al. 1989). The DTS placed on the balance at $15^{\circ} \mathrm{C}$ with a step of $10^{\circ} \mathrm{C} / \mathrm{min}$. The spectrum (Fig. $6 \mathrm{~A}$ ) shows a mass loss of $3.31 \%$ between 100 and $200^{\circ} \mathrm{C}$; water 


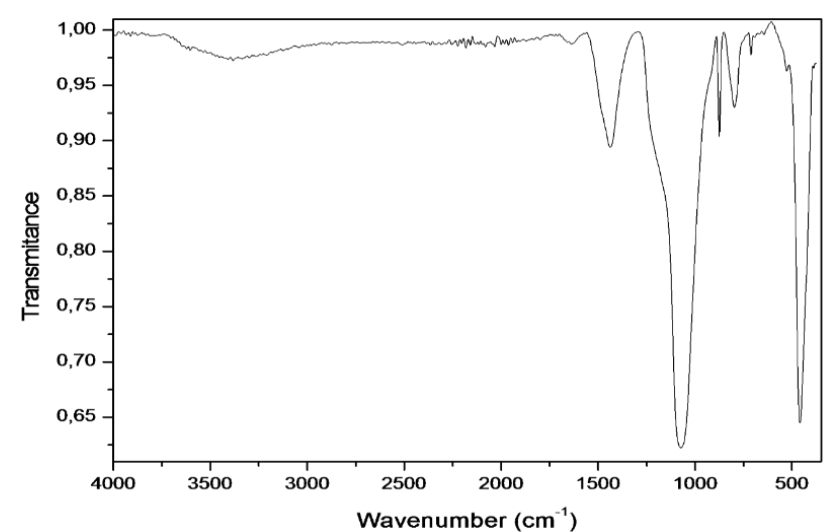

Fig. 5: Fourier Transform Infrared Spectroscopy spectra of diatomite of Sig (DTS).

vapours that escape, represent humidity. The mass loss of $16 \%$ between 300 and $700^{\circ} \mathrm{C}$ corresponds to the decomposition of the organic material and the dehydroxylation of the silanol group. The organic material results primarily from the impurity content of the deposit produced by chemical precipitation, atmospheric contact and environmental conditions, as well as from amorphous silica, the main constituent of diatomite. Metal oxides, clays, carbonates may also be present (Mendioroz et al. 1989). The literature also reports the phenomenon attributed to the dehydroxylation of calcium hydroxide (Benkacem et al. 2016).

As can be seen from the DST results (Fig. 6 B), the first endothermic peak at $106.45^{\circ} \mathrm{C}$ corresponds to water desorption whereas the second, at $689.07^{\circ} \mathrm{C}$, corresponds to the dehydroxylation (Meradi et al. 2015, Mendioroz et al. 1989).

The SEM Examination of the cuticular surfaces of the Dermestes haemorrhoidalis treated with DTS reveals that

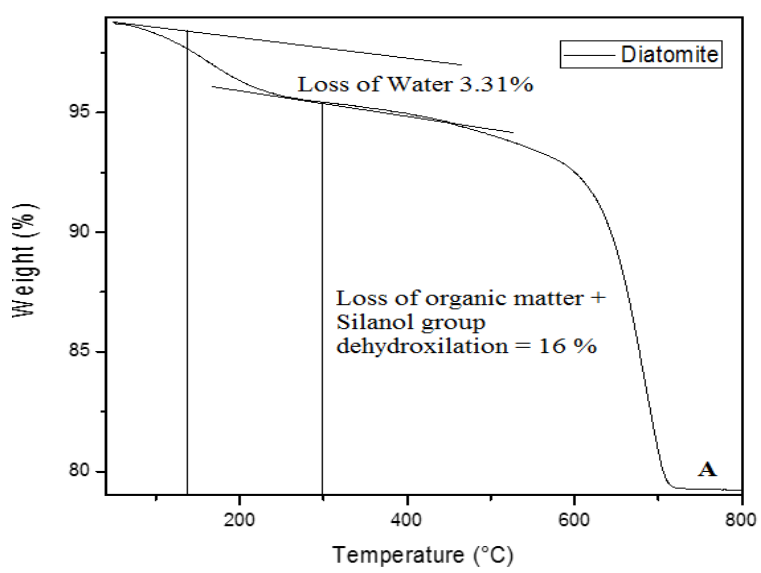

Fig. 6. A: Thermogravimetric Analysis (TGA) of diatomite of Sig (DTS). the dorsal cuticle is evenly covered with fragments of the diatomite frustule on the integumentary surface (Fig. 7).

Table 2 shows the percent mortality of Dermestes haemorrhoidalis at 500 and 1000 ppm of DTS following exposure for 3 different periods of time (2, 7 and 14 days).

The mortality of Dermestes haemorrhoidalis is in agreement with results obtained by Ebeling (1971) and Golob (1997). Indeed, a concentration of $1000 \mathrm{ppm}$ generated mortality of $56.0 \pm 1.15 \%$ after 2 days, $78.7 \pm 0.67 \%$ after 7 days and $90.7 \pm 0.67 \%$ within 14 days, and is higher than the result obtained with $500 \mathrm{ppm}$ with $50.7 \pm 0.67 \%$ after 2 days, $56.7 \pm 4.37 \%$ after 7 days and $80.7 \pm 0.67 \%$ after 14 days.

Table 3: Shows that treatment and exposure time of Dermestes haemorrhoidalis by DTS gives a very significant correlation $(\mathrm{P} \leq 0.001)$.

Complete pest annihilation was not observed for two reasons:

1. The high $\mathrm{RH}$ ( $60 \%$ on average) caused saturation of the DTS and allowed the insect to recover any water loss.

2. In general, diatomite exhibits an activity consistent with its chemical constitution (Athanassiou et al. 2005).

The diatomite of the regions of Sig Algeria, with 90\% efficacy against Dermestes haemorrhoidalis and many other nuisances, can be considered as an appreciable natural insecticide material. Indeed, this non-metallic material offers the sought-after advantage of being, available, low cost, and -biocompatible. It also possesses excellent physicochemical properties such as non-toxicity, lightness, unique structure of the pores, porosity, excellent absorption capacity, chemical inertness and large available reserves (Sun et al. 2013).

Diatomite is an economical and beneficial solution for human, animal and plant health.

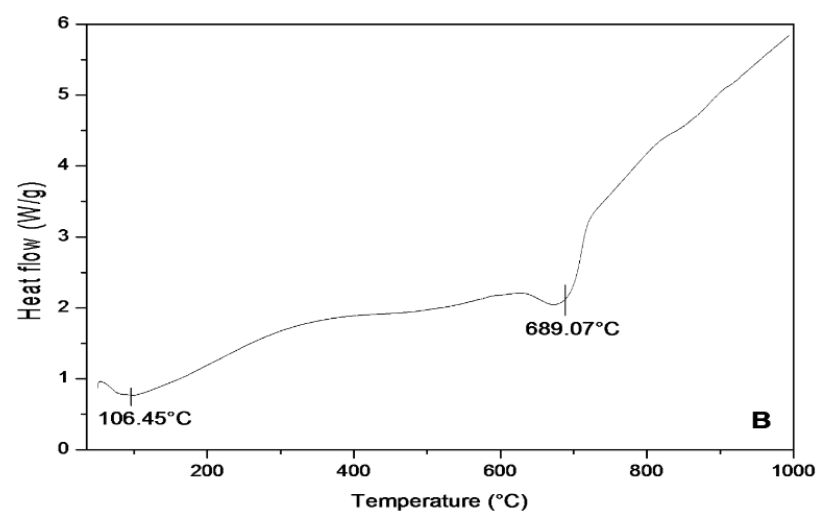

Fig. 6. B: Differential Scanning Calorimetry (DSC) analysis of diatomite of Sig (DTS). 


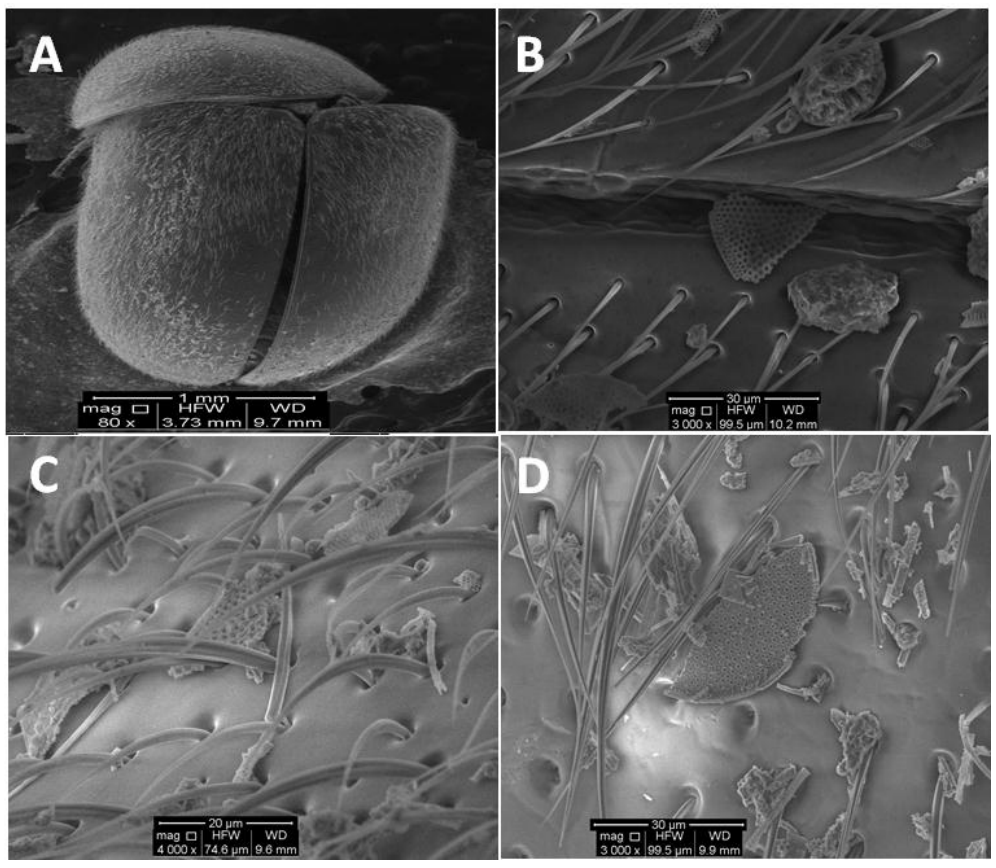

Fig. 7: SEM images of Dermestes haemorrhoidalis treated with diatomite of Sig (DTS) particles, A: dorsal side, B: Fragments of siliceous frustule in the dorsal fringe of the insect, C and D: Cuticular sites on the dorsal surface surrounding sensory bristles contaminated with DTS.

Table 2: Mean ( \pm SE) percent mortality of Dermestes haemorrhoidalis when exposed to diatomite of Sig (DTS) for 2, 7 and 14 days.

\begin{tabular}{|c|c|c|c|}
\hline \multirow{3}{*}{$\begin{array}{l}\text { Duration of } \\
\text { exposure } \\
\text { (days) }\end{array}$} & \multicolumn{2}{|c|}{ Treatment (ppm of DTS) } & \multirow[t]{3}{*}{$\mathrm{F}_{\mathrm{df}}, \mathrm{P}$} \\
\hline & 500 & 1000 & \\
\hline & \multicolumn{2}{|c|}{$\begin{array}{l}\text { Mortality of Dermestes } \\
\text { haemorrhoidalis }\end{array}$} & \\
\hline 2 & $50.7 \pm 0.67 \%$ & $56.0 \pm 1.15 \%$ & $15.7_{1,4}, 0.02$ \\
\hline 7 & $56.7 \pm 4.37 \%$ & $78.7 \pm 0.67 \%$ & $31.7_{1,4}, 0.005$ \\
\hline 14 & $80.7 \pm 0.67 \%$ & $90.7 \pm 0.67 \%$ & $100.1_{1,4},<0.001$ \\
\hline
\end{tabular}

Table 3: ANOVA table showing the significance of treatment and exposure time on mortality of Dermestes haemorrhoidalis.

\begin{tabular}{|ll|}
\hline Variable $_{\mathrm{df}}$ & $\mathrm{F}, P$ \\
\hline Treatment $_{1,12}$ & $90.12,<0.0001$ \\
Exposure $_{2,12}$ & $195.19,<0.0001$ \\
Treatment*Exposure $_{2,12}$ & $12.21,0.001$ \\
\hline
\end{tabular}

\section{CONCLUSION}

The study confirms the natural pest control property of the diatomite from Sig (Algeria). The DTS gives satisfactory results with a mortality rate of $90 \%$ within 14 days on Dermestes haemorrhoidalis, the main pest of wheat in the region of Blida (Algeria). Physicochemical characterisation shows that, by its particular structure, morphology and texture, our diatomite is naturally endowed to control the pest.
This siliceous material is an active structure on the cuticle of the Dermestes haemorrhoidalis. Scanning Electron Microscopy reveals the dispersion and absorbance properties of the diatomite on the cuticle. It also shows the abrasive and lacerating effects of the diatomaceous earth. This control capacity on Dermestes haemorrhoidalis populations highlights the ecological advantage of the diatomite from Sig.

\section{REFERENCES}

Aoues, K., Boutoumi, H. and Benrima, A. 2017. Etat phytosanitaire du blé dur locale stocké en Algérie. Rev. Agrobiologia., 7(1): 286-296.

Athanassiou, C. G., Kavallieratos, N. G., Economou, L. P., Dimizas, C. B., Vayias, B. J., Tomanović, S. and Milutinović, M. 2005. Persistence and efficacy of three diatomaceous earth formulations against Sitophilusoryzae (Coleoptera: Curculionidae) on Wheat and Barley. J. Econ. Entomol., 98(4): 1404-1412.

Athanassiou, C. G., Kavallieratos, N. G., Chiriloaie, A., Vassilakos, T. N., Fătu, V., Drosu, S., Ciobanu, M. and Dudoiu, R. 2016. Efficacy of natural diatomaceous earth deposits from Greece and Romania against four stored grain beetles: the effect of temperature and relative humidity. Bull. Insectology., 69(1): 25-34.

Banks, H.J. and Fields, P. 1995. Physical methods for insect control in stored-grain ecosystems. In. Jayas D, White NDG, MuirWE (Eds.), Stored-grain ecosystems. New York, USA: Marcel Dekker. pp. 353407.

Benkacem, T., Hamdi, B., Chamayou, A., Balard, H. and Calvet, R. 2016. Physicochemical characterization of a diatomaceous upon an acid treatment: a focus on surface properties by inverse gas chromatography. Powder Technol., 294: 498-507. 
Bridgeman, B. 1998. Application technology and usage pattern of diatomaceous earthin stored product protection. In: Proc. 7th Int. Working Conf. on Stored-product Protection, Beijing. Sichuan Publishing House of Science \& Technology, Chengdu, China. pp. 785-789.

Caliskan, N., Kul, A. R., Alkan, S., Sogut, E. G. and Alacabey, I. 2011. Adsorption of Zinc (II) on diatomite and manganese-oxide-modified diatomite: A kinetic and equilibrium study. J. Hazard. Mater., 193: 27-36.

Desmarchelier, J. M., Wright, E. J. and Allen, S. E. 1992. Dryacide (R): a structural treatment for stored-product insects. In: Corey SA, Dall DJ, Milne WM (Eds.), Proceedings of the Australian Applied Entomological Research Conference. Canberra, ACT. pp. 483-485.

Ebadollahi, A. and Sadeghi, R. 2018. Diatomaceous earth and kaolin as promising alternatives to the detrimental chemicals in the management of Spodopteraexigua. J. Entomol., 15(2): 101-105.

Ebeling, W. 1971. Sorptive dusts for pest control. Annu. Rev. Entomol., 16(1): 123-158.

Fragoulis, D., Stamatakis, M. G., Papageorgiou, D. and Chaniotakis, E. 2005. The physical and mechanical properties of composite cements manufactured with calcareous and clayey greek diatomite mixtures. Cem. Concr. Compos., 27(2): 205-209.

Ghorab, M.A. and Khalil, MS. 2016. The effect of pesticides pollution on our life and environment. J. Pollut. Eff. Cont., 4: 159.

Golob, P. 1997. Current status and future perspectives for inert dusts for control of stored product insects. J. Stored. Prod. Res., 33(1): 69-79.

Hazarika, R. 2011. Effect of occupational exposure of pesticides on health of farmers of the agricultural fields of Sorbhug Area of Lower Assam. Nat. Environ. Pollut. Technol., 10(2): 237-241.

Korunić, Z., Rozman, V., Liška, A. and Lucić, P. 2016. A review of natural insecticides based on diatomaceous earths. Poljoprivreda, 22(1): 10-18.

Korunić, Z. 2013. Diatomaceous earths: natural insecticides. Pestic. Phytomed. (Belgrade)., 28(2): 77-95.

Lotti, M. and Moretto, A. 2005. Organophosphate-Induced Delayed Polyneuropathy. Toxicol. Rev., 24(1): 37-49.

Martin-Reina, J., Duarte, J. A., Cerrillos, L., Bautista, J.D. and Moreno, I.G. 2017. Insecticides reproductive toxicity profile: organophosphate, carbamate and pyrethroids. J. Odtoxins., 4(1): 7.

Meiniel, R. 1977. Tératogénie des anomalies axiales induites par un insecticide organophosphoré (le parathion) chez l'embryon d'oiseau. Roux's. Arch. Dev. Biol., 181(1): 41-63.

Mendioroz, S., Belzunce, M. J. and Pajares, J. A. 1989. Thermogravimetric study of diatomites. J. Therm. Anal., 35: 2097-2104.

Meradi, H., Atoui, L., Bahloul, L., Boubendira, K., Ouazdia, A. and Ismail, F. 2015. Characterization by thermal analysis of natural kieselguhr and sand for industrial application. Energy Procedia., 74: 1282-1288.

Mewis, I. and Ulrichs, C. 2001. Action of morphous diatomaceous earth against different stages of the stored product pests Tribolium confusum, Tenebrio molitor, Sitphilusgranarius and Plodiainterpunctella. J. Stored. Prod. Res., 37: 153-164.

Oleobel, A. and Tran, M. 1993. Les Coléoptères des denrées alimentaires entreposées dans les régions chaudes. Orstom/CTA, 425 p.

Pokorný, J., Pavlíková, M., Záleská, M. and Pavlík, Z. 2017. Properties of cement-based composites modified using diatomaceous earth. AIP Conference Proceedings 1866, 040031.

Quarles, W. and Winn, P. S. 1996. Diatomaceous earth and stored product pests. IMP Practitioner, 18(5/6): 1-10.

Richardson, J.R., Fitsanakis, V., Westerink, R.S.H. and Kanthasamy, A.G. 2019. Neurotoxicity pf pesticides. Acta Neuropathologica, 138: 343-362.

Rojht, H., Athanassiou, C. G., Vayias, B. J., Kavallieratos, N., Tomanović, Ž., Vidrih, M., Kos, K. and Trdan, S. 2010. The effect of diatomaceous earth of different origin, temperature and relative humidity against adults of rice weevil (Sitophilus oryzae [L.], Coleoptera, Curculionidae) in stored wheat. Acta. Agric. Slov., 95(1): 13-20.

Steeve, H., Thany, P.R. and Guy, L. 2013. Neurotoxicity of pesticides: its relationship with neurodegenerative diseases. Med. Sci., 29(3): 273-278.

Subramanyam, B. and Roesli, R. 2000. Inert dusts alternatives to pesticides in stored-product IPM. In: Subramanyam B, Hagstrum DW (Eds.), Springer, Boston, MA.

Sun, Z., Yang, X., Zhang, G., Zheng, S. and Frost, R.L. 2013. A novel method for purification of low-grade diatomite powders in centrifugal fields. Int. J. Miner. Process., 125: 18-26.

Testud, F. and Grillet, J.P. 2007. Insecticides organophosphorés, carbamates, pyréthrinoïdes de synthèse et divers. EMC-Pathologie Professionnelle, pp.1-24.

Yuan, P., Wu, D. Q., He, H. P. and Lin, Z. Y. 2004. The hydroxyl species and acid sites on diatomite surface: a combined IR and Raman study. Appl. Surf. Sci., 227: 30-39. 